\title{
Correlation of Pap smear and colposcopic findings in relation to histopathological findings among women attending a tertiary care hospital: a two year study
}

\author{
Jyothi Gandavaram, Bindu Reddy Pamulapati*
}

Department of Obstetrics and Gynecology, Narayana Medical College, Nellore, Andhra Pradesh, India

Received: 01 May 2019

Accepted: 08 May 2019

\section{*Correspondence:}

Dr. Bindu Reddy Pamulapati,

E-mail: sujithbhanu1212@gmail.com

Copyright: (C) the author(s), publisher and licensee Medip Academy. This is an open-access article distributed under the terms of the Creative Commons Attribution Non-Commercial License, which permits unrestricted non-commercial use, distribution, and reproduction in any medium, provided the original work is properly cited.

\begin{abstract}
Background: Cervical malignancy is ranked second among the malignancies in females with breast carcinoma the first. Screening for cervical cancer by conventional cytology and supported by colposcopy and histopathology can easily identify the premalignant lesions and also other non-invasive inflammatory lesions of the cervix. Objective of this study was to find the correlation of Pap smear, colposcopic findings and colposcopic guide biopsy in evaluation of cervical lesions in women and to analyze the various risk factors

Methods: A prospective study for two years was conducted by department of obstetrics among women aged from 2060 years. Socio demographic data, clinical history and examination were done and findings noted. Pap smear, colposcopy and colposcopic guided biopsy was done and findings were noted and analyzed foe sensitivity, specificity and compared with Pap smear.

Results: In present study sensitivity of Pap smear for detecting lesions above LSIL was 28\%, specificity $99.32 \%$, PPV was $93.47 \%$, negative predictive value $76.21 \%$ and accuracy of Pap smear was $78 \%$. The sensitivity of colposcopy in detection of low grade lesions and above came out to be $80.2 \%$, specificity $82.14 \%$, positive predictive value $66.78 \%$, negative predictive value $86.78 \%$ and accuracy of colposcopy was $84.65 \%$. The incidence of preinvasive lesions (LSIL and HSIL) was $33.6 \%$ with LSIL (19.2\%) and HSIL (14.4\%) and of invasive lesions was $9.6 \%$.

Conclusions: This study suggests that accuracy of detection of cervical abnormalities is higher when cytology, colposcopic biopsy and colposcopy are used complimentarily in diagnosis of cervical lesions. Colposcopy eliminates the need for repeated follow up as in Pap smear which has low sensitivity.
\end{abstract}

Keywords: Cervical malignancy, Colposcopy, HSIL, LSIL, Pap smear

\section{INTRODUCTION}

Cervical malignancy is ranked second among the malignancies in females with breast carcinoma the first. The morbidity and mortality resulting due to cervical cancer is more than any other malignancy. Mortality due to cervical cancer is also an indicator of health inequities, as $86 \%$ of all deaths due to cervical cancer are in low income and developing countries. In India, every year 96900 cases are reported and 60000 deaths are registered due to cervical cancer with a median age incidence of 38 years. The relative five year survival averages to $48.7 \% .^{1,2}$ A long phase of preinvasive disease which progresses from cellular atypia to dysplasia or cervical 
intraepithelial neoplasia is identified before progressing to cancer. This prolonged natural history of disease provides best potential for identifying the disease at an early stage by screening which helps in halting the progression and early management. Screening for cervical cancer by conventional cytology and supported by colposcopy and histopathology can easily identify the premalignant lesions and also other non-invasive inflammatory lesions of the cervix. In many developed countries, health education, awareness programs and early detection and appropriate management achieve $80 \%$ reduction in mortality. ${ }^{3}$ Pap smear is the initial simple, safe and effective screening test. The rate of Pap smear performance is only $5 \%$ in developing countries. Hinsellman in 1925 invented colposcopic visualization of cervical epithelium under $6 \mathrm{X}$ and $10 \mathrm{X}$ magnification. It's a simple non-invasive procedure to study benign and premalignant lesions. It also determines the location, size and extent of abnormal cervical lesions and guides to detect the site for biopsies. Pap smear is a laboratory method and colposcopy is a clinical method. Histopathological confirmation is the final gold standard in diagnosis. ${ }^{4}$

The diagnostic algorithms of various organised screening programs include Pap smear, colposcopy and histopathological confirmation. In developing countries, following a strict algorithm for screening is difficult due to insufficient manpower, infrastructure, trained personnel and limitations like low sensitivity and high false negatives. Hence there is a grave need for alternative screening methods in conditions with low and resource poor settings. Hence the present study was aimed to find the correlation of Pap smear, colposcopic findings and colposcopic guide biopsy in evaluation of cervical lesions in women and to analyse the various risk factors.

\section{METHODS}

The present prospective study was conducted by department of Gynaecology in association with department of pathology at a tertiary care hospital for a period of two years from January 2017 to December 2018. The study protocol was presented to the institutional ethical committee and approved. The study was conducted as per the guidelines of the ethical committee. The study protocol was clearly explained and written informed consent was obtained from all the subjects.

\section{Study population}

The study population in the present study include females aged between 20-60 years of age attending the Gynaecology OP departments with clinical history, symptoms suggestive of cervical involvement. A thorough clinical per vaginal examination was done with the help of a speculum and subjects with an unhealthy cervix i.e. erosion of cervix, inflammatory cervix etc. were included in the study. The socio demographic data including age, parity, age at marriage, socio economic status were noted in a separate predesigned questionnaire sheet. A detailed clinical examination was done on the subjects included in the study.

\section{Inclusion criteria}

- Women between 20-60 years of age.

- H/o abnormal vaginal discharge, bleeding, pain abdomen, postcoital bleeding, post-menopausal bleeding, prolapse.

\section{Exclusion criteria}

- Women $<20$ years and $>65$ years.

- Known cases of carcinoma cervix, post hysterectomy, pregnant women.

- Not consented for the study.

\section{Collection of Material}

PAP smear was taken using Ayer's spatula and the scrapings were fixed by dipping the slide in a jar containing 95\% ethyl alcohol and ether. PAP smears were examined by a pathologist and scored based on Revised Bethseda scoring system. ${ }^{5}$

Colposcopic examination was done using colposcope model $150 \mathrm{FC}$ with magnification between $10 \mathrm{X}$ to $12.5 \mathrm{X}$.

\section{The examination included}

- Examination of cervix was done with green filter and saline application.

- Applying 3\% acetic acid to the cervix and observing at junction of squamous cell erosion, papillary lesions, acetowhite areas and vascular designs.

- Findings on colposcopic examination were recorded and diagnosis was made based on Modified colposcopic Reid Index. ${ }^{6}$

- Colposcopic biopsies were performed and stained by hematoxylin and eosin. Findings of the slides were categorized as chronic cervicitis, cervical intraepithelial neoplasia I, II and III, squamous cell carcinoma and adenocarcinoma according to WHO.

\section{Statistical analysis}

The data was entered in a Microsoft excel spread sheet and checked for any corrections. Sensitivity, specificity, positive predictive value (PPV) and negative predictive value (NPV) was calculated.

\section{RESULTS}

In the present prospective study, a total of 250 cases were enrolled based on the inclusion criteria. $39.6 \%$ of cases 
were in 31-40 years age group followed in order by 21-30 years $(26 \%), 41-50$ years (18.4\%) and 51-60 years $(16 \%)$. Majority were $(51.2 \%)$ multiparous (Para 3 or more) and $34.8 \%$ with para 2 and $14 \%$ with para $1.57 .6 \%$ of cases were literate and $42.4 \%$ were illiterate (Table 1).

Table 1: Socio demographic profile.

\begin{tabular}{|lll|}
\hline Age in years & No. of cases & $\%$ \\
\hline $20-30$ & 65 & 26 \\
\hline $31-40$ & 99 & 39.6 \\
\hline $41-50$ & 46 & 18.4 \\
\hline $51-60$ & 40 & 16 \\
\hline Parity & & \\
\hline Para 1 & 35 & 14 \\
\hline Para 2 & 87 & 34.8 \\
\hline Para 3 and more & 128 & 51.2 \\
\hline Literacy & & \\
\hline Literate & 144 & 57.6 \\
\hline Illiterate & 106 & 42.4 \\
\hline
\end{tabular}

White discharge was the most common clinical symptom $(55.2 \%)$ among the cases and others were post coital bleeding (13.6\%), low backache $(17.6 \%)$, postmenopausal bleeding (13.6\%), pain abdomen $(8.4 \%)$ and menstrual disorders $(11.2 \%)$ (Table 2$)$.

Table 2: Distribution of cases based on symptoms.

\begin{tabular}{|lll|}
\hline Presenting symptoms & No of cases & $\%$ \\
\hline White discharge & 138 & 55.2 \\
\hline Post coital bleeding & 34 & 13.6 \\
\hline Pain in abdomen & 21 & 8.4 \\
\hline Low backache & 44 & 17.6 \\
\hline Post-menopausal bleeding & 34 & 13.6 \\
\hline Menstrual disorders & 28 & 11.2 \\
\hline
\end{tabular}

Table 3: Distribution of colposcopic findings.

\begin{tabular}{|llll|}
\hline $\begin{array}{l}\text { S. } \\
\text { No. }\end{array}$ & Reid Colposcopic score & $\begin{array}{l}\text { No of } \\
\text { cases }\end{array}$ & $\%$ \\
\hline 1 & $0-2$ (Benign Inflammatory) & 146 & 58.4 \\
\hline 2 & $3-5$ (Low grade) & 58 & 23.2 \\
\hline 3 & $6-8$ (high grade) & 34 & 13.6 \\
\hline 4 & $>8$ carcinoma & 12 & 4.8 \\
\hline Total & & 250 & 100 \\
\hline
\end{tabular}

All the cases were examined by colposcope and graded as per Reid colposcopic score as, benign inflammatory (Score 0-2), low grade (score 3-5), high grade (Score 6-8) and if $>8$ considered as carcinoma. Based on the scoring system, majority were benign inflammatory $58.4 \%$, low grade $23.25 \%$, high grade $13.6 \%$ and $4.8 \%$ as carcinoma (Table 3).

Pap smears were stained and examined and the findings were recorded as NILM (Negative for intraepithelial lesion or malignancy) with 67.2\%, ASCUS (Atypical squamous cells of undermined significance) with $13.6 \%$, LSIL (Low grade squamous intra epithelial lesion) with 9.6\%, HSIL (High grade squamous intra epithelial lesion) with $6.4 \%$ and carcinoma in $3.2 \%$ (Table 4). Table 5 summarizes the findings of histopathological findings among the cases in the study with $56.8 \%$ with chronic cervicitis with metaplasia, 19.2\% LSIL, $14.4 \%$ HSIL and $9.6 \%$ carcinomas.

Table 4: Distribution of various grades of cytology (Pap smear).

\begin{tabular}{|lll|l|}
\hline S. No. & Types of smear & No. of cases & $\%$ \\
\hline 1 & NILM & 168 & 67.2 \\
\hline 2 & ASC $($ US $)$ & 34 & 13.6 \\
\hline 3 & LSIL & 24 & 9.6 \\
\hline 4 & HSIL & 16 & 6.4 \\
\hline 5 & Carcinoma & 8 & 3.2 \\
\hline Total & & 250 & 100 \\
\hline
\end{tabular}

Table 5: Distribution of various grades of histopathology.

\begin{tabular}{|c|c|c|c|}
\hline S. No. & $\begin{array}{l}\text { Histopathological } \\
\text { finding }\end{array}$ & No of cases & $\%$ \\
\hline 1 & Chronic cervicitis & 142 & 56.8 \\
\hline 2 & $\begin{array}{l}\text { LSIL (Mild } \\
\text { dysplasia) }\end{array}$ & 48 & 19.2 \\
\hline 3 & $\begin{array}{l}\text { HSIL (Moderate To } \\
\text { severe) }\end{array}$ & 36 & 14.4 \\
\hline 4 & Carcinoma & 24 & 9.6 \\
\hline Total & & 250 & 100 \\
\hline
\end{tabular}

LSIL: Low grade squamous intraepithelial lesion, HSIL: High grade squamous intraepithelial lesion

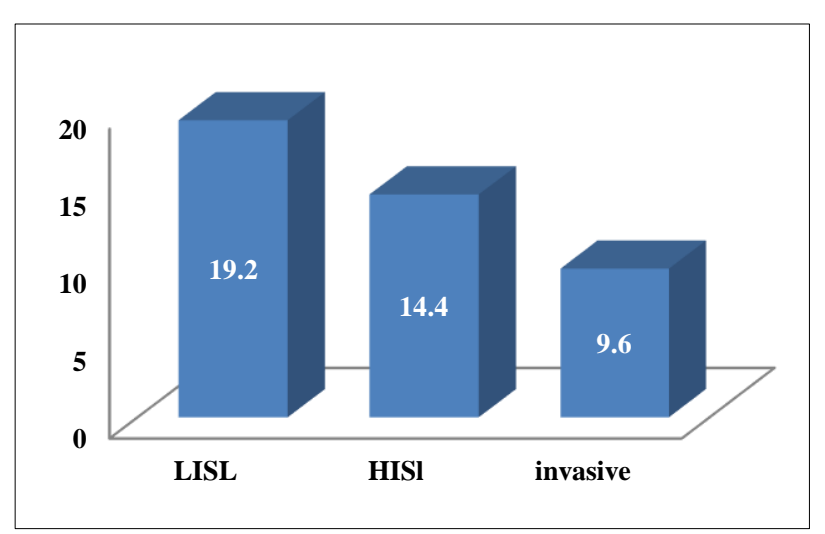

Figure 1: Incidence of pre-invasive and invasive lesions in the study (\%).

The overall sensitivity of Pap smear for detecting lesions above LSIL was $28 \%$, specificity $99.32 \%$, PPV was $93.47 \%$, negative predictive value $76.21 \%$ and accuracy of Pap smear in our study was $78 \%$. Table 6 summarizes the correlation between Pap smear and histopathological findings in our study. 
Table 7 describes the correlation between colposcopic findings and histopathological findings of our study. In the present study, the sensitivity of colposcopy in detection of low grade lesions and above came out to be $80.2 \%$, specificity $82.14 \%$, positive predictive value $66.78 \%$, negative predictive value $86.78 \%$ and accuracy of colposcopy in our study was $84.65 \%$.
The incidence of preinvasive lesions (LSIL and HSIL) was $33.6 \%$ with LSIL (19.2\%) and HSIL (14.4\%). The incidence of invasive lesions in our study was $9.6 \%$ (24/250) (Figure 1).

Table 6: Correlation between pap smear report and histopathological report.

\begin{tabular}{|llllll|}
\hline \multirow{2}{*}{ Pap Smear } & \multicolumn{1}{l}{ Histopathological report } & & \\
& Chronic cervicitis & LSIL (Mild dysplasia) & HSIL (Moderate To severe) & Carcinoma & Total \\
\hline NILM & $124(49.6 \%)$ & $24(9.6 \%)$ & $12(4.8 \%)$ & $8(3.2 \%)$ & 168 \\
\hline ASC (US) & $4(1.6 \%)$ & $17(6.8 \%)$ & $6(2.4 \%)$ & $7(2.8 \%)$ & 34 \\
\hline LSIL & $12(4.8 \%)$ & $6(2.4 \%)$ & $4(1.6 \%)$ & $2(0.8 \%)$ & 24 \\
\hline HSIL & $2(0.8 \%)$ & & $11(4.4 \%)$ & $3(1.2 \%)$ & 16 \\
\hline Carcinoma & & $1(0.4 \%)$ & $3(1.2 \%)$ & $4(1.6)$ & 8 \\
\hline Total & $142(56.8 \%)$ & $48(19.2 \%)$ & $36(14.4 \%)$ & $24(9.6 \%)$ & 250 \\
\hline
\end{tabular}

Table 7: Correlation between colposcopic findings and histopathological report.

\begin{tabular}{|llllll|}
\hline $\begin{array}{l}\text { Colposcopic } \\
\text { finding }\end{array}$ & Histopathological report & & \\
\hline Abnormal & Chronic cervicitis & LSIL (Mild dysplasia) & HSIL (Moderate To severe) & Carcinoma & Total \\
\hline $\begin{array}{l}\text { 0-2 (Benign } \\
\text { Inflammatory) }\end{array}$ & $120(48 \%)$ & $15(6 \%)$ & $11(4.4 \%)$ & 0 & 146 \\
\hline 3-5 (Low grade) & $20(8 \%)$ & $25(10 \%)$ & $11(4.4 \%)$ & $2(0.8 \%)$ & 58 \\
\hline 6-8 (high grade) & $2(0.8 \%)$ & $8(3.2 \%)$ & $14(5.6 \%)$ & $10(4 \%)$ & 34 \\
\hline$>8$ carcinoma & & $48(19.2 \%)$ & $36(14.4 \%)$ & $12(4.8 \%)$ & 12 \\
\hline Total & $142(56.8 \%)$ & $24(9.6 \%)$ & 250 \\
\hline
\end{tabular}

\section{DISCUSSION}

In the present study, 31-40 years age group was the most common group and this indicates that premalignant lesions (dysplasia) precede the development of malignancy by a decade and prompt identification by appropriate screening reduces the mortality and morbidity associated with cervical cancer. Multiparous women were more common in our study $(51.2 \%)$ indicating that women with early sexual exposure in early life and more children are associated with more chance of abnormal findings in screening for cervical premalignant lesions. The mean parity of women in our study was 3 which is similar to findings of Goel et al. ${ }^{7}$ Abnormal colposcopic findings are more common in women with post coital bleeding and post-menopausal bleeding which indicate that they are significant risk factors for malignancy of cervix. All these finding sin our study correlates with the findings of Arora $\mathrm{R}$ et al. ${ }^{8}$

White discharge per vaginum was the most common symptom in our study $(55.2 \%)$ as compared with the studies of Chaudhary RD et al. ${ }^{9}$ Few studies reported post coital bleeding as one of the major complaint, which is contrary to the finding in our study, however the study group in that study was age group $>60$ years. In the present study by colposcopy, $58.4 \%$ of cases were benign inflammatory (Score 0-2) followed by low grade (3-5), high grade and carcinoma (>8). Findings of our study correlate with the findings of Krishnegowda and Veena. ${ }^{10}$ Colposcope has the ability to localize and determine the extent of all lesions which will not be visible to the naked eye and can be detected in single setting. It also helps in determining the site of biopsy, patients for conservative treatment of CIN, follow up of intraepithelial neoplasia and invasive lesions. On Pap smear, majority of the cases reported were NILM (67.2\%), and frank malignancy was reported in $3.2 \%$ of cases and LSIL and HSIL in $9.6 \%$ and $6.4 \%$. Findings of our study coincide with the findings of Bal MS et al. ${ }^{11}$ However findings in the study of Shastri SS et al, $95.4 \%$ were normal, $0.026 \%$ had LSIL, $0.01 \%$ has HSIL and $0.007 \%$ had invasive carcinoma. ${ }^{12}$ These differences in Pap smear reporting's are due to differences in sampling, staining, fixation techniques and reporting errors.

On Histopathological examination, majority of the cases in the present study were of chronic cervicitis and 
infection (56.8\%) followed by mild dysplasia (19.2\%), moderate to severe in $14.4 \%$ and $9.6 \%$ malignant lesions. Findings of our study coincide with the reports of Bodal and Brar who reported malignancy in $8.5 \%$ of cases in his study. ${ }^{13}$ In the present study, overall sensitivity of Pap smear for detecting lesions above LSIL was $28 \%$ and accuracy was $28 \%$. Findings of our study coincide with findings of Joshi et al who reported the same with a sensitivity of $30 \%$, PPV of $94 \%$ and accuracy of $79 \%$ in his study. ${ }^{14} \mathrm{~A}$ few studies with different sample size, age group reported a sensitivity of up to $45 \%$. In the present study, the sensitivity of colposcopy in detection of low grade lesions and above came out to be $80.2 \%$, specificity $82.14 \%$, positive predictive value $66.78 \%$, negative predictive value $86.78 \%$ and accuracy of colposcopy was $84.65 \%$. Study by Ramesh $\mathrm{G}$ et al also reported the same in their study but our findings were contrary to the reports of Mallur PR et al who reported sensitivity of colposcopy in detection of low grade lesions as high as $90 \%$ and accuracy of $78 \%$ with specificity of $76 \%$ in their study. ${ }^{15,16}$

Hence the present study strongly suggests that colposcopy and colposcopic directed biopsy of cervix should be included along with the Pap smear in screening of cases for early detection of cervical cancer and usage increases the accuracy of detection of cervical abnormalities is higher when used complementarily.

\section{CONCLUSION}

Cervical cancer is a preventable and curable malignancy if identified and managed early. However early lesions of cervical cancer, i.e. CIN and early invasive stages are asymptomatic. Hence regular screening after 40 years should be made mandatory and a best screening procedure to detect early lesions should be made available in low resource settings. In India, Pap smear still remains as a screening tool because of low resources and settings. Our study indicates that colposcopy is more sensitive tool than Pap smear in identification of early lesions. But Pap smear is more specific tool in diagnosing CIN than colposcopy for screening. Hence our study suggests that accuracy of detection of cervical abnormalities is higher when cytology, colposcopic biopsy and colposcopy are used complimentarily in diagnosis of cervical lesions. Colposcopy eliminates the need for repeated follow up as in Pap smear which has low sensitivity.

\section{Funding: No funding sources}

Conflict of interest: None declared

Ethical approval: The study was approved by the Institutional Ethics Committee

\section{REFERENCES}

1. World health organization. Cervical Cancer Screening in Developing Countries [Internet]. Geneva: World health organization; 2002:1-75.
Available from: https://www.who.int/cancer/media/en/cancer_cervica 1_37321.pdf. (accessed 21 November 2014).

2. Bobdey S, Sathwara J, Jain A, Balasubramaniam G. Burden of cervical cancer and role of screening in India. Indian J Med Paediatr Oncol. 2016 OctDec;37(4):278-285.

3. Pandey K, Bhogoliwal A: Cancer cervix- need for mass surveillance program specially in Rural areas. J Obstet Gynecol India. 2005;55(5):436-9.

4. Vinay K, Abbas AK, Aster JC. Robbins and Cotran Pathologic Basis of Disease. 9th ed. Chicago: Elsevier Science Health Science Division; 2015.

5. Addis IB, Hatch KD, Berek JS. Intraepithelial disease of the cervix, vagina and vulva. Berek and Novak's Gynaecology $14^{\text {th }}$ Edn Lippincott Williams and Wilkins 2007;573.

6. Reid R, Scalzi P. Genital warts and cervical cancer. VII. An improved colposcopic index for differentiating benign papilloma viral infections from high-grade cervical intraepithelial neoplasia. Am J Obstet Gynecol. 1985;153(6):611-8.

7. Goel A, Gandhi G, Batra S, Bhambani S, Zutshi V, Sachdeva P. Visual inspection of the cervix with acetic acid for cervical Intraepithelial lesions. Dept of Obstetrics and Gynaecology, Maulan Azad medical college, new Delhi, India. Int J Gynecol Obstet. 2005;88(1):25-30.

8. Arora R, Vijaya K, Habeebullah S, Asha O. Colposcopic evaluation of unhealthy cervix. J Obstet Gynecol Ind. 2000;50:102-3.

9. Chaudhary RD, Inamdar SA, Hariharan C. Correlation of diagnostic efficacy of unhealthy cervix by cytology, colposcopy and histopathology in women of rural areas. Int $\mathbf{J}$ Reprod Contracept Obstet Gynecol. 2014;3(1):213-8.

10. Krishnegowda S, Veena MS. Efficacy of coiposcopy technique with Pap smear and histology in screening of cervical lesions. Int J Repord Contracept Obstet Gynecol. 2014;3(3):696-702.

11. Bal MS, Goyal R, Suri AK, Mohi MK. Detection of abnormal cervical cytology in Papanicolaou smears. J Cytol. 2012 Jan-Mar;29(1):45-7.

12. Shastri SS, Dinshaw K, Amin G, Goswami S, Patil S, Chinoy R, et al. Concurrent evaluation of Visual cytological and HPV testing as screening methods for the early detection of cervical neoplaisia in Mumbai, India. Bull World Healthy Organ. 2005;83(3):186-94.

13. Bodal VK, Brar BK. Correlation of pap smear with histopathological findings in malignant and nonmalignant lesions of cervix. Glob J Med Res E Gynecol Obstet. 2014;14:19-23.

14. Joshi C, Kujur P, Thakur N. Correlation of pap smear and colposcopy in relation to histopathological findings in detection of premalignant lesions of cervix in a tertiary care centre. Int $\mathbf{J}$ Sci Stud. 2015;3(8):55-60. 
15. Ramesh G, Sudha R, Jayashree AK, et al. Colposcopic evaluation of unhealthy cervix. J Clin and Diagnos Res. 2012;6(6):1026-8.

16. Mallur PR, Desai BR, Anita D, Geeta D, Bhavana S, Pallav G. Sequential screening with cytology and colposcopy in detection of cervical Neoplasia. J South Asian Fed Obstet Gynaecol. 2009;1(3):45-8.
Cite this article as: Gandavaram J, Reddy BP. Correlation of Pap smear and colposcopic findings in relation to histopathological findings among women attending a tertiary care hospital: a two year study. Int J Reprod Contracept Obstet Gynecol 2019;8:2163-8. 